\title{
Functional interactions between the transcription and mRNA 3' end processing machineries mediated by Ssu72 and Sub1
}

\author{
Xiaoyuan He, ${ }^{1}$ Asad U. Khan, ${ }^{2}$ Hailing Cheng, ${ }^{1}$ Donald L. Pappas Jr., ${ }^{2}$ Michael Hampsey, ${ }^{2}$ and \\ Claire L. Moore ${ }^{1,3}$ \\ ${ }^{1}$ Department of Molecular Biology and Microbiology, Tufts University School of Medicine, Boston, Massachusetts 02111, \\ USA; ${ }^{2}$ Department of Biochemistry, Robert Wood Johnson Medical School, Piscataway, New Jersey 08854, USA
}

\begin{abstract}
Transcription and processing of pre-mRNA are coupled events. By using a combination of biochemical, molecular, and genetic methods, we have found that the phylogenetically conserved transcription factor Ssu72 is a component of the cleavage/polyadenylation factor (CPF) of Saccharomyces cerevisiae. Our results demonstrate that Ssu72 is required for 3' end cleavage of pre-mRNA but is dispensable for poly(A) addition and RNAP II termination. The in vitro cleavage defect caused by depletion of $S s u 72$ from cells can be rescued by addition of recombinant Ssu72. Ssu72 interacts physically and genetically with the Pta1 subunit of CPF. Overexpression of PTA1 causes synthetic lethality in an ssu72-3 mutant. Moreover, Sub1, which has been implicated in transcription initiation and termination, also interacts with Pta1, and overexpression of SUB1 suppresses the growth and processing defect of a pta1 mutation. Physical interactions of Ssu72 and Sub1 with Pta1 are mutually exclusive. Based on the interactions of Ssu72 and Sub1 with both the Pta1 of CPF and the TFIIB component of the initiation complex, we present a model describing how these novel connections between the transcription and $3^{\prime}$ end processing machineries might facilitate transitions in the RNAP II transcription cycle.
\end{abstract}

[Keywords: RNAP II; transcription initiation; transcription termination; 3' end processing; cleavage/ polyadenylation]

Received January 14, 2003; revised version accepted February 24, 2003.

Eukaryotic pre-mRNAs undergo several processing events before maturation, including addition of a cap structure to the $5^{\prime}$ terminus of nascent transcripts, removal of introns by splicing, and formation of the poly(A) tail at the $3^{\prime}$ end. This maturation occurs cotranscriptionally in vivo and is facilitated by the recruitment of mRNA processing factors to the phosphorylated C-terminal domain (CTD) of the RNA polymerase II (RNAP II) largest subunit (for reviews, see Bentley 2002; Howe 2002; Maniatis and Reed 2002; Orphanides and Reinberg 2002; Proudfoot et al. 2002). A major focus of current research is understanding the mechanism and functional consequences of coupling transcription with these mRNA processing events.

The achievement of this goal has been helped by our increasing knowledge of the components of the core cleavage/polyadenylation machinery. Several complexes

${ }^{3}$ Corresponding author.

E-MAIL claire.moore@tufts.edu; FAX (617) 636-0337.

Article and publication are at http://www.genesdev.org/cgi/doi/10.1101/ gad.1075203. act in concert to recognize and process the pre-mRNA $3^{\prime}$ ends (for reviews, see Zhao et al. 1999a; Edmonds 2002; Shatkin and Manley 2000). In Saccharomyces cerevisiae, accurate cleavage of pre-mRNA requires cleavage factor I (CFI) and cleavage/polyadenylation factor $(\mathrm{CPF})$, whereas poly(A) addition requires $\mathrm{CFI}, \mathrm{CPF}$, and the poly(A) binding protein (Pab1). CFI is composed of the Rna14, Rna15, Pcf11, Clp1, and Hrp1 polypeptides. CPF includes seven subunits that are known to function in cleavage and polyadenylation (Cft1/Yhh1, Cft2/Ydh2, Brr5/Ysh1, Pta1, Pfs2, Yth1, and Mpe1) and two (Pap1 and Fip1) that are specific for the poly(A) addition step (Wahle and Ruegsegger 1999; Zhao et al. 1999b; Vo et al. 2001). Counterparts of the CFI and CPF complexes have been identified in higher eukaryotes, underscoring the conserved nature of this essential process (Edmonds 2002; Shatkin and Manley 2000; Zhao et al. 1999a).

Recently, we and others have used affinity purification of CPF to show that several additional proteins that have not previously been implicated in mRNA 3' end formation are nonetheless stably associated with this complex (Roguev et al. 2001; Dichtl et al. 2002a; Gavin et al. 2002; 
Walsh et al. 2002; this study). One of these subunits is Ssu72, a protein that is essential for cell viability in $S$. cerevisiae and is highly conserved among eukaryotic organisms. No homologs of Ssu72 have been identified in prokaryotes or Archea, suggesting that the function of Ssu72 is specific to eukaryotes.

The yeast SSU72 gene was initially identified based on a genetic interaction with $S U A 7$, the gene encoding the general transcription factor TFIIB (Sun and Hampsey 1996). Yeast strains that are mutant for both sua7 and ssu72 exhibit a synthetic growth defect and a dramatic enhancement of the downstream start site shift associated with defective TFIIB (Sun and Hampsey 1996). The link between Ssu72 and transcription is further supported by the identification of $r b p 1$ and $r p b 2$ alleles, encoding altered forms of the two largest subunits of RNAP II, as suppressors of the ssu72-2 mutation (Pappas and Hampsey 2000; M. Reyes and M. Hampsey, unpubl.). The ssu72-2 allele adversely affects noninduced RNAP II transcription with little or no effect on RNAP I or RNAP III transcription (Pappas and Hampsey 2000). Ssu72 directly binds RNAP II, and this interaction occurs, at least in part, through the Rpb2 subunit (Pappas and Hampsey 2000; Dichtl et al. 2002a).

The yeast Sub1 protein was also identified based on a genetic interaction with TFIIB. Subl exhibits sequence similarity to the human transcriptional coactivator PC4 (Ge et al. 1994; Henry et al. 1996), and Sub1 affects both basal and activated transcription in vitro (Henry et al. 1996). The SUB1 gene was initially isolated as a high copy suppressor of an sua7 mutation that affects start site selection (Knaus et al. 1996). Furthermore, sub1s and ssu72 mutations exhibit the same pattern of allelespecific interactions with sua7 (Wu et al. 1999). Consistent with these genetic interactions, Sub1 and Ssu72 directly bind TFIIB (Knaus et al. 1996; Wu et al. 1999). These results imply a functional relationship between Sub1 and Ssu72, and suggest that both proteins are involved in transcription initiation mediated by TFIIB.

Interestingly, the CFI subunit, Rna15, and its mammalian homolog, CstF p64, also interact with the Sub1 and PC4 proteins, respectively, in a manner that is thought to inhibit the termination activity of CFI (Calvo and Manley 2001). In light of this Sub1-CFI connection and the relationship between Sub1 and Ssu72, the association of Ssu72 with the CPF complex is especially intriguing. Do Sub1 and Ssu72, in addition to their roles in transcription, also affect mRNA 3' end processing? To explore this possibility, we used a combination of biochemical and genetic assays to investigate the interactions of Ssu72 and Sub1 with the CPF complex and to determine their effects on mRNA 3 ' end processing. We demonstrate that Ssu72 physically and genetically interacts with the Ptal subunit of CPF and is directly involved in cleavage of pre-mRNA but not in poly(A) addition. It is also an unusual cleavage factor in that it is not required for transcription termination. Surprisingly, we also found that Ptal physically and genetically interacts with Subl and that Ptal cannot simultaneously bind to Ssu72 and Sub1, suggesting that sequential pair- ing with different partners may regulate the activity of these three proteins at different steps in mRNA synthesis. These results define two novel and physiologically significant points of contact between the transcription and mRNA $3^{\prime}$ end processing machineries.

\section{Results}

\section{Ssu72 is associated with CPF}

To isolate proteins that interact with the Ptal subunit of $\mathrm{CPF}$, we used the tandem affinity purification (TAP) method (Puig et al. 2001), which takes advantage of an epitope containing both protein A and a calmodulinbinding peptide. By using extract prepared from a yeast strain in which a TAP-tagged version of Ptal was the sole source of Ptal, we found that Ptal was associated with known CPF subunits such as Cft1, Cft2, Brr5, Pta1, Pap1, Pfs2, Fip1, and Yth1 and several novel proteins that included Ref2, Mpe1, Pti1, Swd2, Glc7, Ssu72, and YOR179C (Fig. 1A). The CFI proteins and Pab1 were not detected in the purified CPF (data not shown). This profile of CPF-associated proteins is in accord with that found by several other groups using TAP-tagged CPF subunits (Roguev et al. 2001; Dichtl et al. 2002a; Gavin et al. 2002; Walsh et al. 2002). The fact that Ssu72, a transcription initiation factor that interacts with TFIIB, copurified with the CPF complex is particularly interesting and suggests a potential connection between the cleavage/polyadenylation and transcriptional machineries.

To further confirm the specific association of Ssu72 with CPF, we constructed a yeast strain (named here as SSU72-td) that expresses the fusion protein UbiquitinArg-DHFR ${ }^{\text {ts }}$-HA-Ssu72, and performed coimmunoprecipitation assays with extract prepared from this strain. Known components of CPF are brought down with antibody against the HA epitope on the Ssu72 fusion but not with antibody against Pip1, an extraneous protein (Fig. 1B, lanes 1,3). The anti-HA antibody failed to immunoprecipitate the Rna15 subunit of CFIA. Taken together, these results support the idea that Ssu72 is an integral subunit of CPF.

\section{Ssu72 interacts with the Pta1 subunit of CPF both in vitro and in vivo}

We next used GST pull-down assays to determine which CPF components interacted directly with Ssu72. A strong interaction was detected between Ssu72 and Pta1 (Fig. 2A). Ssu72 interacted weakly but specifically with Pcf11, Cft2, Brr5, and Pfs2, whereas interactions with Rna14, Rna15, Fip1, Yth1, Pap1, Clp1, or Hrp1 were undetectable (Fig. 2A; data not shown). These interactions do not depend on the presence of RNA, as similar results were obtained when samples were treated with RNase A (data not shown). The direct interaction of Ssu72 and Ptal was further confirmed by coimmunoprecipitation assays using anti-Ptal antibody and by GST pull-down 
He et al.

Figure 1. Ssu72 is associated with the cleavage/ polyadenylation factor (CPF). (A) Affinity purification of proteins associated with TAP-tagged Pta1. Protein was isolated from a yeast strain expressing TAP-tagged Ptal by using IgG-agarose beads and eluted by TEV protease cleavage (lane 2). The complex was further purified by using calmodulin beads and eluted with EGTA (lane 3). Proteins were separated on a $10 \%$ polyacrylamide-SDS gel and stained with silver. The sizes of protein markers (lane 1) in kilodaltons are indicated on the left. (B) CPF subunits coimmunoprecipitate with Ssu72 from whole-cell extract of SSU72-td cells expressing Ubiquitin-Arg-DH$\mathrm{FR}^{\mathrm{ts}}$-HA-Ssu72. Proteins were immunoprecipitated with anti-HA (lanes 1,2) or anti-Pip1 (lanes $3,4)$ antibodies bound to protein A agarose beads. Immunoprecipitates (IP) and 10\% of the supernatants (SN) were resolved by a $10 \%$ polyacrylamide-SDS gel. Proteins were detected with antibodies as indicated on the right.

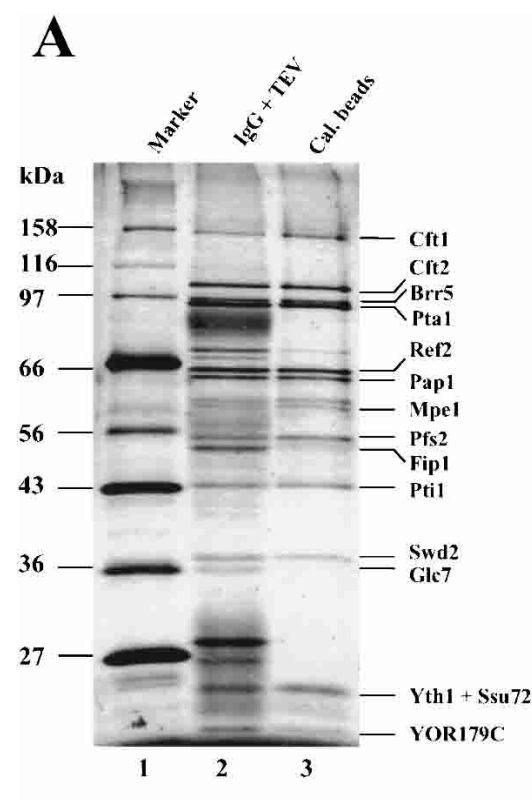

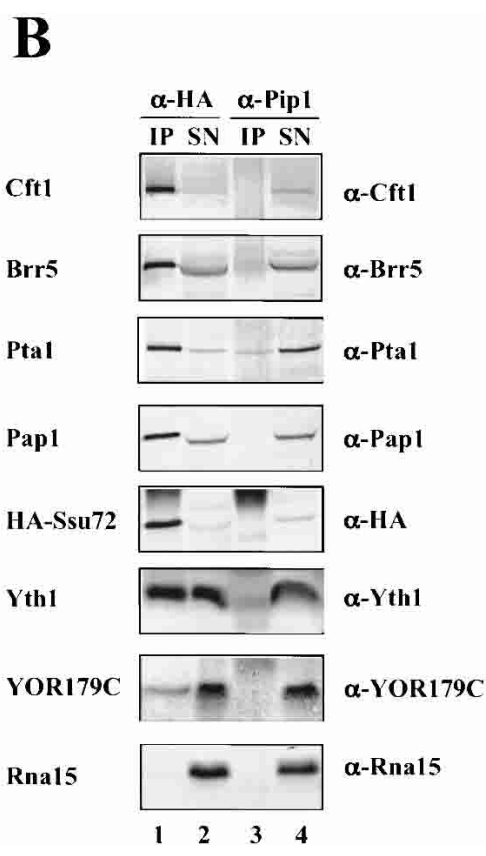

Based on the genetic and physical interactions between Ssu72 and Ptal, we next investigated the importance of Ssu72 in mRNA 3' end processing in vivo. For this purpose, we examined the types of RNA14 mRNA produced in the ssu72-3 mutant, which is not viable when PTA1 is overexpressed. The RNA14 gene produces three transcripts that vary in length at their $3^{\prime}$ ends through the use of different cleavage sites (Fig. 2C; Minvielle-Sebastia et al. 1991). Wild-type yeast enhance processing of the upstream poly(A) site under stressful conditions such as growth on a poor carbon source or at high temperature (Mandart 1998; Sparks and Dieckmann 1998), and mutations in the CFI subunits Rna14 and Rna15 prevent this shift (Mandart 1998). Northern blot analysis revealed that the ssu72-3 mutant made less of the 1.1-kb RNA14 transcript at $25^{\circ} \mathrm{C}$ compared with wild-type cells, and did not increase usage of this site after shift to growth at $37^{\circ} \mathrm{C}$ (Fig. 2D).

\section{Ssu72 is required for $3^{\prime}$ end processing in vitro}

The analysis described above suggests that Ssu72 is important for accurate regulation of RNA14 3' end processing in vivo. However, we do not know whether increased use of the RNA14 upstream processing site in wild-type cells is due to preferred selection of this site from multiple poly(A) sites on a single transcript or to increased termination immediately downstream of the first site. An additional caveat to interpreting this data is that the steady-state levels of these mRNAs could be subject to differential changes in stability. To more directly test whether Ssu72 was involved in cleavage and polyadenylation and/or transcription termination, we used in vitro processing and transcription run-on assays.

Whole cell extracts from isogenic wild-type and ssu72 temperature-sensitive mutant strains grown at $25^{\circ} \mathrm{C}$ 


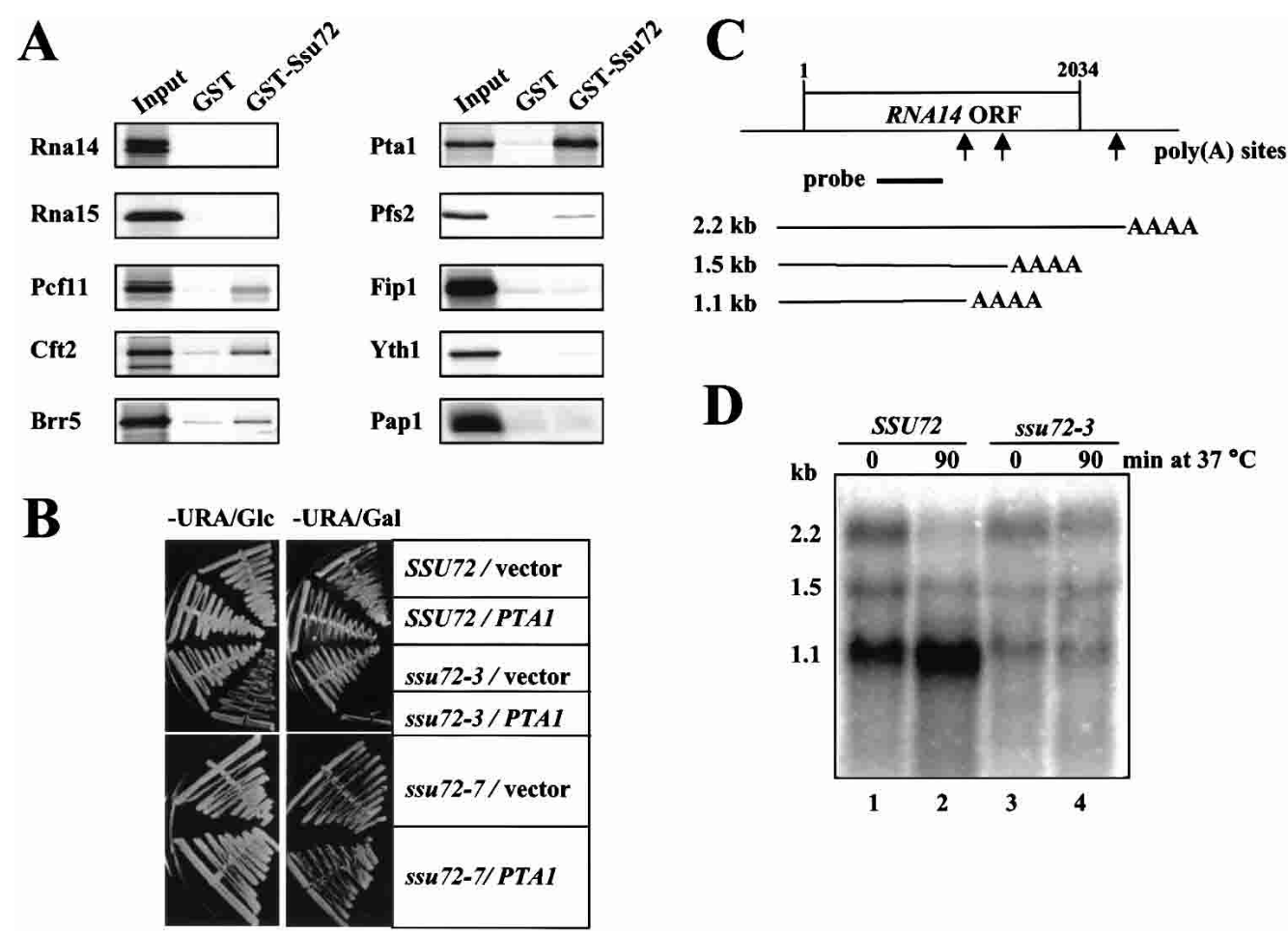

Figure 2. Ssu72 interacts with Ptal and is required for accurate cleavage of RNA14 mRNA in vivo. (A) Ssu72 interacts directly with Pta1. Recombinant GST-Ssu72 or GST alone was bound to glutathione-Sepharose beads and then incubated with proteins radioactively labeled by in vitro translation. The proteins bound to GST or GST-Ssu72 and 10\% of the input were separated on a $10 \%$ polyacrylamide-SDS gel and detected by autoradiography. (B) Overexpression of PTA1 is lethal in combination with the ssu72-3 mutation. Isogenic SSU72 wild-type, ssu72-3, and ssu72-7 strains were transformed with the URA3 plasmids pYES (vector) or pYES-PTA1 (PTA1), from which PTA1 is expressed under the control of a galactose-inducible promoter. Purified transformants were streaked on synthetic medium lacking uracil (-URA) and containing either $2 \%$ glucose (-URA/Glc) or $2 \%$ galactose (-URA/Gal) as the sole carbon source and incubated for $2 \mathrm{~d}$ at $30^{\circ} \mathrm{C}$. (C) Schematic representation of RNA14 gene and its transcripts. Arrows indicate the poly(A) sites. The position of the DNA fragment used as the probe in Northern blot analysis is indicated by a black bar. (D) Northern blot analysis of RNA14 mRNA showing poly(A) ${ }^{+}$mRNAs from $100 \mu \mathrm{g}$ of total RNA isolated from the ssu72-3 mutant (lanes 3,4) or isogenic wild-type SSU72 (lanes 1,2) cells grown at $25^{\circ} \mathrm{C}$ (lanes 1,3) or shifted for $90 \mathrm{~min}$ to $37^{\circ} \mathrm{C}$ (lanes 2,4$)$. The approximate size of each transcript is indicated in kilobases on the left.

were tested for in vitro $3^{\prime}$ end processing activity at $30^{\circ} \mathrm{C}$ by using a synthetic radiolabeled GAL7 precursor RNA. As seen for wild-type extract (Fig. 3A, lanes 2,8), this substrate is efficiently cleaved, and all cleaved RNA is polyadenylated. The ssu72 extracts show activity comparable to the isogenic controls (Fig. 3A, cf. lanes 2 and 5, lanes 8 and 11 and 14). However, the activities of the ssu72-2, ssu72-3, and ssu72-7 mutants were dramatically reduced compared with wild type when extracts were preincubated at $37^{\circ} \mathrm{C}$ (Fig. 3A). There was no accumulation of cleaved unadenylated RNA.

To discriminate between effects of ssu72 mutations on cleavage or poly(A) addition, poly(A) addition assays were carried out by using an RNA substrate containing only sequences upstream of the GAL7 poly(A) site. Heat treatment of the ssu72-2 and ssu72-3 mutant extracts had no effect on poly(A) addition when compared with wild-type extracts, although poly(A) addition appeared to be mildly impaired after prolonged heat treatment of the ssu72-7 extract (Fig. 3B). Taken together, our results indicate that Ssu72 is required for execution of cleavage but is dispensable for poly(A) addition. This unusual property defines Ssu72 as the first yeast cleavage factor that does not also function in poly(A) addition.

We next tested whether the processing defect can be complemented with extracts prepared from strains containing mutations in CFIA and CPF subunits. As described previously (Minvielle-Sebastia et al. 1994; Zhao et al. 1999b), extracts from rna14-1, rna15-2, or pta1-2 strains were defective for processing in vitro (Fig. 3C, lanes 4-6), but were able to rescue the defective activity of the heat-treated ssu72-3 extract (Fig. 3C, lanes 7-9). Similar results were also obtained with the ssu72-2 and ssu72-7 extracts (data not shown).

Temperature-sensitive mutants often exhibit reduced levels of not only the mutant protein but also other wildtype proteins that interact with the mutant protein. For example, levels of the Pta1, Cft1, and Brr5 subunits of $\mathrm{CPF}$ are reduced in pta1 mutant extracts (Zhao et al. 1999b). Western blot analysis showed that the amount of Ptal and other CPF or CFI subunits were not affected in ssu72 mutant extracts in comparison with wild-type, and were not changed on heat treatment of extract (Fig. $3 \mathrm{D})$. We were not able to assay Ssu72 in mutant extracts 
He et al.
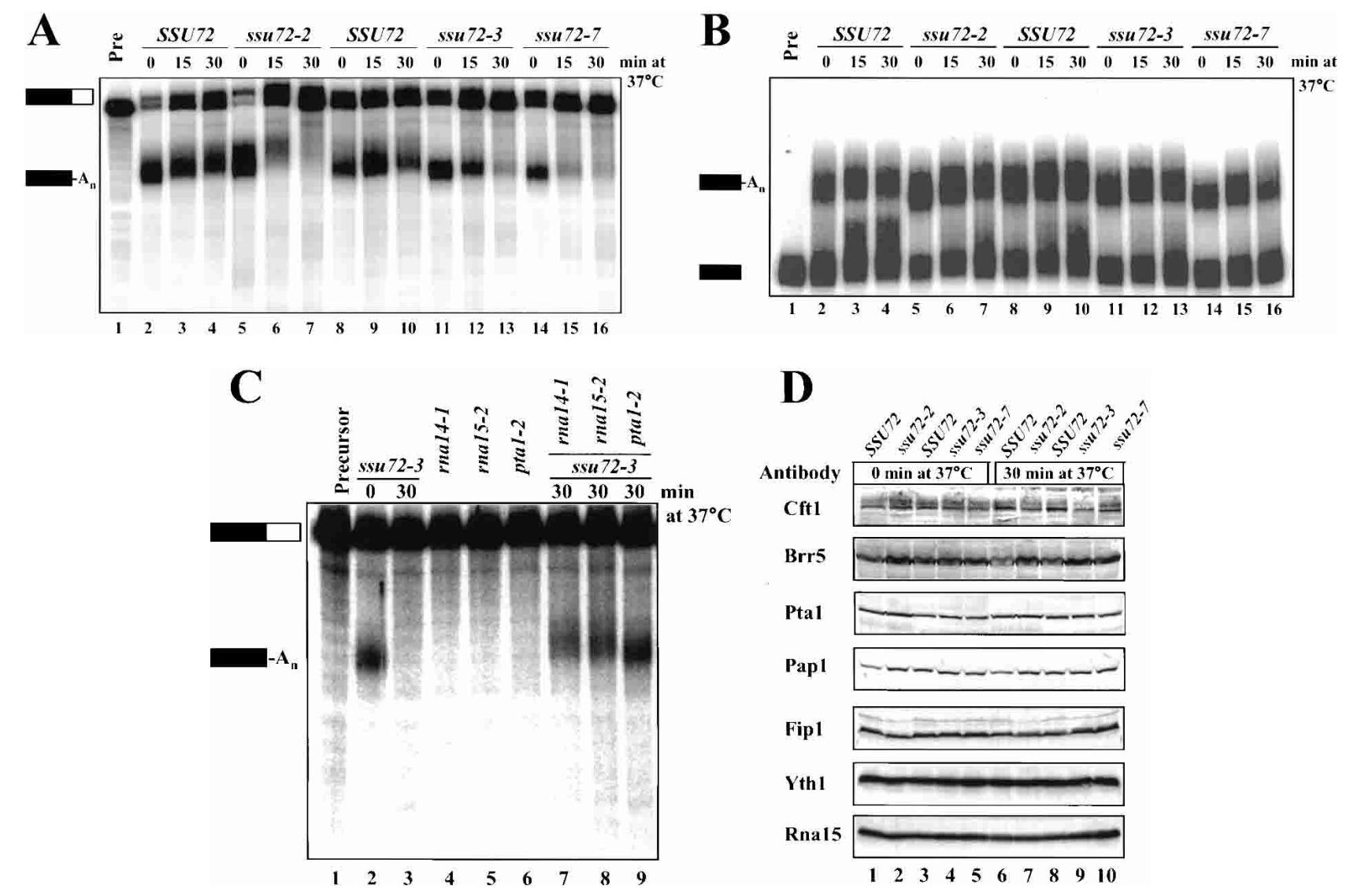

Figure 3. Ssu72 is required for in vitro $3^{\prime}$ end processing. (A) Coupled cleavage/polyadenylation assays. Extracts (70 $\left.\mu \mathrm{g}\right)$ from ssu72 mutants (lanes 5-7,11-16) or the isogenic wild-type strains (lanes 2-4,8-10) were incubated with ATP and ${ }^{32} \mathrm{P}-1$ labeled full-length GAL7-1 RNA (lane 1, precursor) for $20 \mathrm{~min}$ at $30^{\circ} \mathrm{C}$. Products were resolved on a denaturing $5 \%$ polyacrylamide gel and visualized with a PhosphorImager. In some cases, extracts were heated at $37^{\circ} \mathrm{C}$ for the indicated times before adding to the reaction mixture. Positions of the precursor RNA and products are shown by the bars on the left. The downstream cleavage product is rapidly degraded and not visible. (B) Poly(A) addition assays. The assays were performed as in $A$ except that precleaved RNA substrate GAL7-9 (lane 1) was used as precursor. $(C)$ Complementation of processing activity in the heat-treated ssu72-3 mutant extract. Reactions were carried out as in $A$ with extracts as indicated at the top of each lane. $(D)$ Western blot analysis of whole-cell extracts prepared from ssu 72 mutants and isogenic wild-type strains. Equal amounts of protein $(70 \mu \mathrm{g})$ from wild type and ssu72 mutants as indicated on the top of each lane were separated on a $10 \%$ polyacrylamide-SDS gel and proteins detected with antibodies as shown on the left. In some cases, extracts were heated for $30 \mathrm{~min}$ at $37^{\circ} \mathrm{C}$.

because Ssu72 antibody is not available. However, Dichtl et al. (2002a) have shown that the ssu72-2 mutant protein is stable at $37^{\circ} \mathrm{C}$, indicating that heat treatment of our extracts is probably affecting Ssu72 function rather than stability. The Western blot analysis, the retention of efficient poly(A) addition, and the rescue of ssu72 mutant extracts suggest that Ssu72 is the only component of the $3^{\prime}$ end processing machinery that is perturbed by the heat treatment, and support the conclusion that Ssu72 is directly involved in 3' end processing.

\section{Levels of Pta1 and Ssu72 are tightly coordinated in vivo}

To further investigate the function of Ssu72, we depleted Ssu72 in vivo by using the degron strategy (Dohmen et al. 1994), which is based on integrating a heat-inducible degradation signal (Ubiquitin-Arg-DHFR ${ }^{\text {ts }}$ ) in frame with the $\mathrm{N}$ terminus of the gene of interest. This fusion also introduces a HA epitope for detection of the fusion protein. Cells (SSU72-td) expressing this Ssu72 fusion protein grow at $25^{\circ} \mathrm{C}$ with no growth defect but arrest after shift to $37^{\circ} \mathrm{C}$ (data not shown), consistent with SSU72 being an essential gene (Sun and Hampsey 1996). The Ssu 72 protein is rapidly degraded after shift to $37^{\circ} \mathrm{C}$ and is not detectable after $30 \mathrm{~min}$ (Fig. 4A, lane 4). Surprisingly, the level of Ptal, but not that of other CPF and CFI subunits, decreased on Ssu72 depletion (Fig. 4A). These results are consistent with the strong physical and genetic interactions between Ssu72 and Pta1 (Fig. 2) and indicate that the amounts of Ssu72 and Ptal are tightly coordinated in vivo.

Extracts were prepared from the SSU72-td strain at different time points after shift to $37^{\circ} \mathrm{C}$ and assayed for in vitro processing activity. Extracts from cells grown at $25^{\circ} \mathrm{C}$ efficiently cleaved and polyadenylated the precur- 


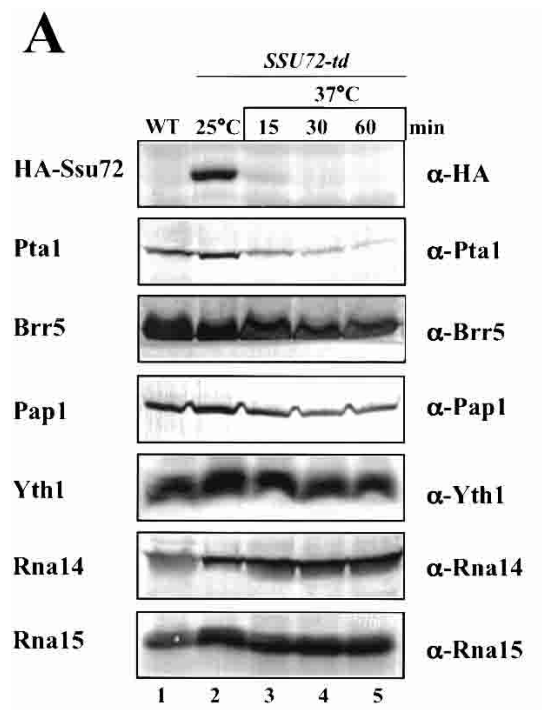

B

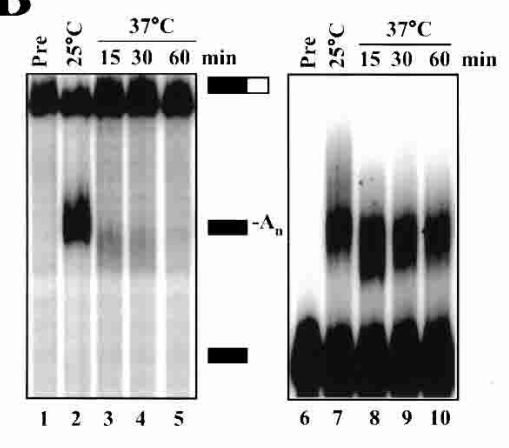

C

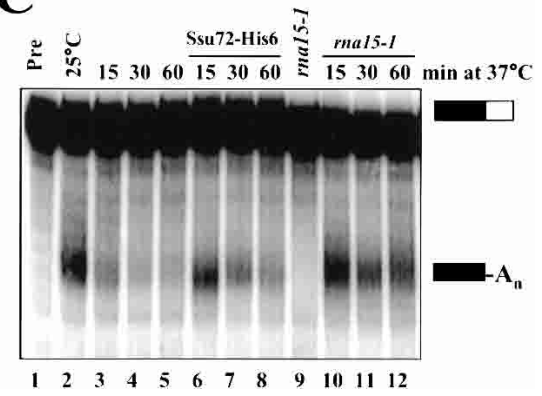

Figure 4. In vivo depletion of Ssu72 affects the cleavage step of pre-mRNA 3 ' end processing. (A) The level of Ptal decreases on Ssu72 depletion in vivo. Western blot analysis was performed with extracts from wild-type (WT, lane 1) or SSU72-td (lanes 2-5) cells grown at $25^{\circ} \mathrm{C}($ lanes 1,2$)$ or shifted to $37^{\circ} \mathrm{C}$ for the indicated times (lanes 3-5). Antibodies used are indicated on the right. (B) Depletion of Ssu72 in vivo affects in vitro $3^{\prime}$ end processing. The coupled cleavage/polyadenylation assay (lanes 2-5) was carried out as described in Figure 3A with the extracts $(70 \mu \mathrm{g})$ from the SSU72-td strain described in $A$. Poly(A) addition assays (lanes 7-10) were performed as described in Figure 3B. Unreacted precursor (Pre) is shown in lanes 1 and $6 .(C)$ Recombinant Ssu72-His6 can rescue the Ssu72-depleted extract. Extract $(35 \mu \mathrm{g})$ from each Ssu72-depletion (lanes 3-5) was supplemented with $200 \mathrm{ng}$ of Ssu72-His6 (lanes 6-8) or rna15-1 extract (lanes 10-12). (Lane 1) Unreacted precursor. (Lane 9) Activity of the rna15-1 extract. sor RNA (Fig. 4B, lane 2). However, extracts from cells after the shift to $37^{\circ} \mathrm{C}$ were defective in processing (Fig. $4 \mathrm{~B}$, lanes 3-5). In contrast, the effects of Ssu72 depletion on poly(A) addition were much less pronounced (Fig. 4B, lanes 7-10), and are most likely due to loss of Ptal, which is important for both steps (Zhao et al. 1999b). The differential effect of Ssu72 depletion on cleavage and poly(A) addition is evident as early as $15 \mathrm{~min}$ after the shift to $37^{\circ} \mathrm{C}$ (Fig. 4B, lane 3). At this time point, the loss of Ssu72 protein coincides with a clear loss of cleavage activity, with no effect on poly(A) addition.

Addition of recombinant Ssu72-His6 or defective rna15-1 extract can rescue an extract prepared after a 15-min depletion to a level comparable to that of undepleted extract (Fig. 4C). Rescue by recombinant protein after longer depletion times was not as effective, probably because of the concomitant loss of Ptal. Exogenously added Ssu72-His6 has no effect on the rna15-1 extract (data not shown), indicating that the rescue is specific for the Ssu72-depleted extract. These results confirm that Ssu72 is directly involved in cleavage but not poly(A) addition.

\section{The ssu72 mutants do not affect transcription termination}

The findings that the CFIA subunits Rna14, Rna15, and Pcf11 and the CPF subunit Cft1 are required for proper transcription termination downstream of poly(A) sites (Birse et al. 1998; Dichtl et al. 2002b) prompted us to investigate whether Ssu72 affects termination. For this purpose, we performed transcription run-on analysis (TRO) using the CYC1 gene (Birse et al. 1998). This assay involves incubating permeabilized yeast cells in a tran- scription buffer that inhibits initiation but allows elongation over a short distance. Radioactive RNA synthesized in these cells is hybridized to immobilized singlestrand DNA probes complementary to different regions of the CYC1 reporter gene (Fig. 5A). In wild-type cells, RNAP II transcription rapidly declines beyond the polyadenylation site, indicating termination of transcription (Fig. 5A). A similar hybridization pattern is seen for the ssu $72-2$ mutant grown at $25^{\circ} \mathrm{C}$ and $37^{\circ} \mathrm{C}$. To ensure that we could detect transcription beyond the poly(A) site if it was occurring, we examined transcription from the rna15-1 mutant, which is known to give read-through transcription at $37^{\circ} \mathrm{C}$ (Birse et al. 1998). In this case, a strong signal was seen with the downstream probes.

Quantitative analysis of the data for wild type and ssu72-2 cells is presented in Figure 5B. Similar results were obtained by using the ssu72-3 and ssu72-7 mutants (data not shown). While this work was in progress, a similar result for ssu72-2 was reported by Dichtl et al. (2002a) for cells grown continuously in galactose-containing medium. We did not examine termination efficiency using the conditions in which they observed stalling of RNAP II upstream of the CYC1 processing site on Ssu 72 inactivation (growth in $2 \%$ raffinose, $0.08 \%$ glucose, followed by a shift to $2 \%$ galactose).

Because the ssu72-2, ssu72-3, and ssu72-7 alleles may not affect the domain of Ssu72 involved in termination, we tested the effect of Ssu72 depletion. In the SSU72-td strain at $25^{\circ} \mathrm{C}$, the levels of transcription through regions C4-C6 of the reporter gene are higher than those in strains used for the experiment with ssu72-2. However, there is no increase at all in read-through transcription on shifting the SSU72-td strain to $37^{\circ} \mathrm{C}$ for $45 \mathrm{~min}$ (Fig. $5 \mathrm{~B})$, a time when Ssu72 is no longer detectable and cleav- 
He et al.
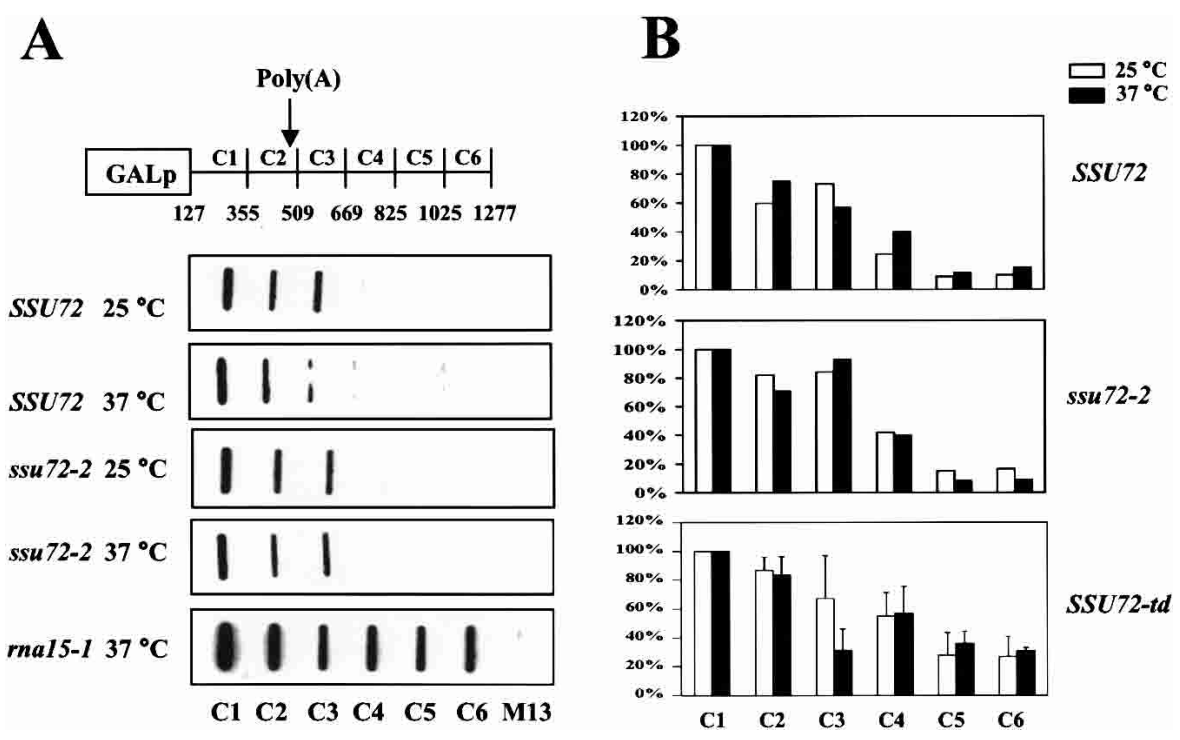

Figure 5. The ssu72 mutants do not affect transcription termination. (A) Transcription run-on (TRO) analysis. Locations of the probes $(\mathrm{C} 1-\mathrm{C} 6)$ and the poly(A) site on the $C Y C 1$ reporter gene are indicated. Yeast strains carrying the $\mathrm{pCYC} 1$ plasmid were grown at $25^{\circ} \mathrm{C}$, or shifted to $37^{\circ} \mathrm{C}$ for $45 \mathrm{~min}$ before the TRO analysis. (B) Quantification of TRO data by PhosphorImager analysis. The signal from each probe was normalized according to the U content and corrected for the M13 background signal. The data were then normalized to the C1 probe, which was fixed at $100 \%$. For SSU72 and ssu72-2, the results of two independent experiments were averaged. SSU72-td represents the average of three different experiments.

age activity is almost completely lost (Fig. 4). Taken together, these results indicate that Ssu72 does not have a role in transcription termination.

\section{Sub1 physically and genetically interacts with Pta1}

The functional relationship between Ssu72 and Sub1 (see Introduction) prompted us to investigate whether Sub1 might also interact with Pta1. By GST pull-down assay, a GST-Ptal fusion interacted as strongly with in vitro translated Sub1 as does GST-TFIIB (Fig. 6A, lanes 3,5). The same assay showed no interaction between GSTSsu72 and Sub1 (Fig. 6A, lane 4). A complex of His6tagged Ptal and Sub1 could also be detected by immunoprecipitation with Ptal-specific antibody, although in this case, a trace amount of Subl bound nonspecifically in the absence of Ptal (Fig. 6A, lanes 6,7). These interactions were resistant to RNase A treatment (data not shown). We cannot rule out that the interaction of Pta1 and Subl is mediated by a protein endogenous to the reticulocyte lysate used for in vitro translation, but the genetic interactions described below make this possibility unlikely.

We investigated the significance of the in vitro interaction by asking whether Ptal and Sub1 interact genetically. Indeed, high-copy expression of SUB1 from a $2 \mu$ HIS3 plasmid strongly suppressed the pta1-2 thermosensitive growth phenotype, but had no effect on either wild-type cells or the pta1-3 mutant (Fig. 6B). These results define an allele-specific genetic interaction between thermosensitive pta1 and SUB1 and suggest that the physical interaction between Ptal and Subl is physiologically significant.
We next tested whether SUB1, which is dispensable for cell viability, is rendered essential in combination with pta1-2. The pta1-2 mutant was transformed with the URA3 plasmid pYCp-PTA1, and SUB1 was then deleted from its chromosomal locus. As expected, the wildtype and sub1s strains exhibited normal growth at $25^{\circ} \mathrm{C}$ (Fig. 6C, top and bottom sectors). The strains were then placed on medium containing 5-fluoroorotic acid, which counter-selects pYCp-PTA1. Whereas the pta1-2 SUB1 strain remains viable, the pta1-2 sub1s failed to grow (Fig. 6C, right panel). This result defines a synthetic lethal relationship between pta1-2 and sub1s, a result that is consistent with suppression of pta1-2 by SUB1 overexpression and provides further evidence of a functional interaction between Subl and Ptal in vivo.

\section{Sub1 compensates for the defective activity of pta1-2 in vitro}

We next asked whether suppression of the pta1-2 growth defect by high-copy SUB1 expression reflects a role for Sub1 in $3^{\prime}$ end processing. Extracts from wild type, pta1-2 mutant, and SUB1 overexpressing strains were assayed for processing in vitro. Consistent with suppression of the pta1-2 growth defect by SUB1 overexpression, processing activity is restored in the pta1-2 mutant by high copy SUB1 expression but not by vector alone (Fig. 6D). It is possible that restoration of pta1-2 activity is due to an indirect effect of SUB1 overexpression, which is known to stimulate transcriptional activation in vivo (Knaus et al. 1996). To address this issue, we performed Western blot analysis by using the same processing extracts. We observed no increase in the amount 


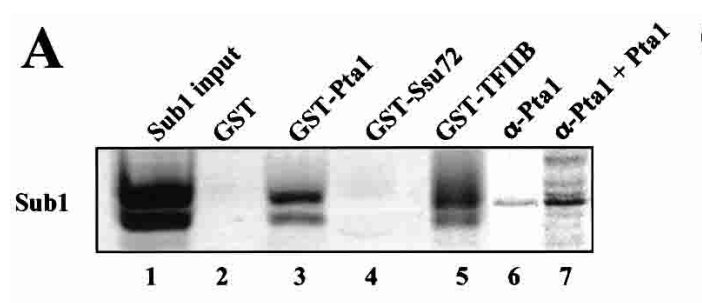

\section{B}
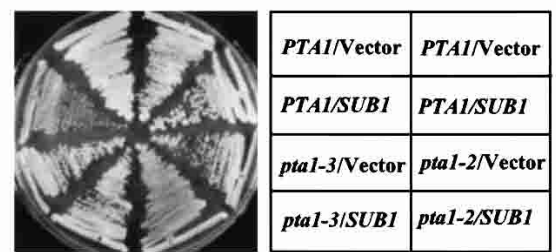

$30^{\circ} \mathrm{C}$

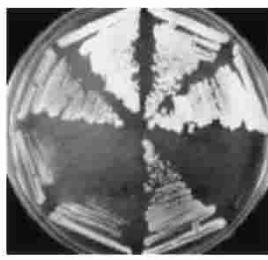

$37^{\circ} \mathrm{C}$

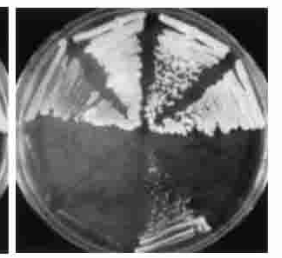

$38.5^{\circ} \mathrm{C}$
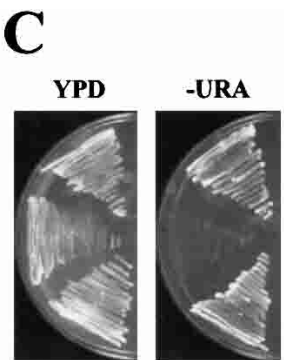

5-FOA
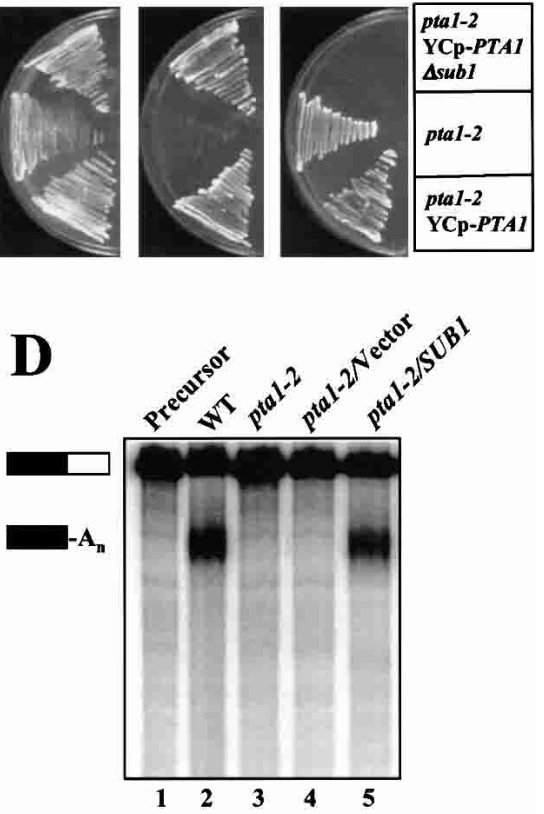

Figure 6. Sub1 physically and genetically interacts with Pta1. (A) Sub1 directly interacts with Pta1 and TFIIB but not Ssu72. For lanes 1-5, recombinant GST-Pta1, GST-Ssu72, GST-TFIIB, or GST alone (as indicated at the top of each lane) was bound to glutathioneSepharose beads and incubated with in vitro translated $\left[{ }^{35} \mathrm{~S}\right]$-Subl. Ten percent of the Sub1 input (lane 1) and all of the bound proteins were separated on a $10 \%$ polyacrylamide-SDS gel. For lanes 6 and $7,\left[{ }^{35} \mathrm{~S}\right]$-Sub1 was incubated with anti-Ptal bound to protein A agarose beads in the presence or absence of $\left[{ }^{35} \mathrm{~S}\right]$-Pta1-His6. (B) Overexpression of SUB1 suppresses the pta1 thermo-sensitive phenotype in an allele-specific manner. The PTA1, pta1-2, and pta1-3 strains were transformed with a $2 \mu$ HIS3 SUB1 plasmid or vector (pRS423) alone. Transformants were purified on -His medium and incubated on rich medium at $30^{\circ} \mathrm{C}, 37^{\circ} \mathrm{C}$, or $38.5^{\circ} \mathrm{C}$ for $2 \mathrm{~d}$. Strains on the left side of each plate are derivatives of XH6 (PTA1) and XH15 (pta1-3); strains on the right side are derivatives of FY23 (PTA1) and FY1284 (pta1-2). (C) Deletion of SUB1 causes synthetic lethality in the pta1-2 mutant. Plasmid YCp-PTA1 was introduced into the pta1-2 mutant, and a resulting transformant was disrupted at the chromosomal SUB1 locus. The pta1-2 host strain (middle sector), pta1-2 mutant transformed with YCp-PTA1 (bottom sector), and its sub1s derivative (upper sector) were then streaked onto rich medium (YPD), synthetic medium lacking uracil (-URA), and synthetic medium that counter-selects the URA3 plasmid (5-FOA), and incubated at $25^{\circ} \mathrm{C}$ for 3-5 d. (D) Overexpression of $S U B 1$ restores the processing activity of the pta1-2 mutant. Coupled cleavage/ polyadenylation reactions were performed with extracts from wild type (WT, lane 2), pta1-2 (lane 3), pta1-2/vector (lane 4), and pta1-2/SUB1 (lane 5). Precursor RNA is shown in lane 1. Positions of the precursor RNA and polyadenylated products are indicated by the bars on the left.

of Ptal in the pta1-2 strain overexpressing SUB1 (data not shown), indicating that Sub1 levels do not affect PTA1 expression. Taken together, our results suggest that extra Sub1 compensates for the defective 3' end processing activity of pta1-2.

\section{Sub1 cannot bind to Pta1 in the presence of Ssu72}

By GST pull-down assays, we have shown that Ptal interacts with Ssu72 and Sub1, and that Ssu72 does not interact with Sub1. Furthermore, SSU72 and SUB1 genetically interact with pta1 in an allele-specific manner. These results prompted us to ask whether the Ssu72 and Sub1 interaction with Ptal is mutually exclusive. In vitro translated, His6-tagged $\left[{ }^{35} \mathrm{~S}\right]-\mathrm{Pta} 1$ and $\left[{ }^{35} \mathrm{~S}\right]-\mathrm{Sub} 1$ were mixed and immunoprecipitated with Ptal antibody, resulting in recovery of both Pta1 and Sub1, (Fig. 7, lane 8). However, only Ptal could be detected when GST-Ssu72 instead of anti-Ptal antibody was used to isolate Ptal from the same mixture of Ptal and Sub1 (Fig. 7, lane 7). These results indicate that Ptal does not simultaneously bind to Ssu72 and Sub1.

\section{Discussion}

In this paper, we define an unexpected link between the transcription initiation and pre-mRNA 3' processing machineries. We have found that Ssu72 is an integral subunit of the CPF complex, a conclusion supported by two other recent studies (Dichtl et al. 2002a; Gavin et al. 2002). Moreover, we demonstrate that Ssu 72 is an essential pre-mRNA cleavage factor but is not involved in either poly(A) addition or transcription termination. Ssu 72 interacts physically and genetically with the Pta1 


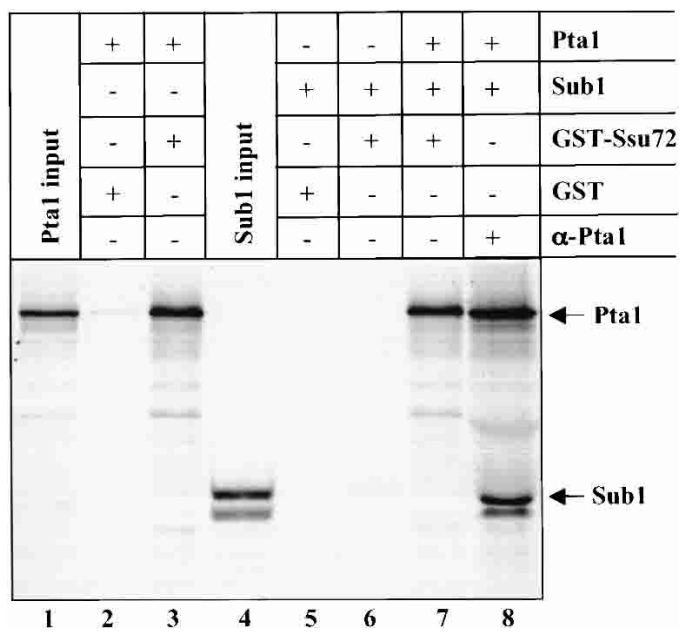

Figure 7. Sub1 cannot bind to Ptal in the presence of Ssu72. Recombinant GST-Ssu72 (lanes 3,6,7) or GST alone (lanes 2,5) was bound to glutathione-Sepharose beads and then incubated with in vitro translated Ptal (lanes 2-3,7) and/or Subl (lanes 5-7). For lane 8, the same amount of in vitro translated Ptal and/or Sub1 as used in lane 7 were incubated with anti-Pta1 antibody bound to protein A agarose beads. Proteins bound to the beads and $10 \%$ of the input of in vitro translated Ptal (lane 1) and Sub1 (lane 4) were separated on a $10 \%$ polyacrylamideSDS gel.

subunit of CPF. Surprisingly, Ptal also interacts with Sub1, a transcription initiation and termination factor, and the Ssu72 and Sub1 interactions with Ptal are mutually exclusive. In the present study, we discuss the significance and implications of these findings and present a model for how Ssu72 and Sub1 might interact with the transcription initiation and $3^{\prime}$ processing machineries to affect the RNAP II transcription cycle.

Ssu72 was initially identified based on genetic and physical interactions with the TFIIB and RNAP II components of the transcription initiation machinery (Sun and Hampsey 1996; Pappas and Hampsey 2000). Furthermore, ssu72 mutations affect start site selection in combination with a specific TFIIB defect. Those studies point to an important, albeit undefined, role for Ssu72 in initiation. Our data showing that Ssu72 is directly involved in pre-mRNA cleavage suggest that Ssu72 functions in the synthesis of both the $5^{\prime}$ and $3^{\prime}$ ends of mRNAs. This new activity of Ssu72 provides an alternative explanation for the strong decrease in total poly $(\mathrm{A})^{+}$RNA levels observed with the ssu72-2 mutant (Pappas and Hampsey 2000), as this effect is commonly seen with mutations in 3' end processing factors (Minvielle-Sebastia et al. 1991) and is thought to be mediated by an exosome-dependent mechanism (Torchet et al. 2002). E. Nedea and J. Greenblatt (pers. comm.) have recently found that Ssu72 also has a role in the formation of snoRNA $3^{\prime}$ ends.

Cleavage and polyadenylation in vitro readily occurs on exogenous substrate in the absence of transcription. However, recent work has elegantly demonstrated that 3 ' end processing in vivo happens most efficiently if it takes place cotranscriptionally (for reviews, see Bentley
2002; Howe 2002; Maniatis and Reed 2002; Proudfoot et al. 2002). RNAP II increases the efficiency of mRNA 3' end processing through interactions between the RNAP II CTD and processing factors. In addition, a reciprocal interaction exists, with transcription termination downstream of poly(A) sites, as measured by transcription runon assays, occurring most efficiently in the presence of authentic processing signals and a functional cleavage apparatus. Mutation of factors needed only for poly(A) addition have no effect on termination (Birse et al. 1998). In the present study, we show that the ssu72 mutations, unlike other cleavage-defective mutants, do not impair transcription termination. This result may be related to the recent findings using in vitro assays (Tran et al. 2001) and EM visualization of RNAP II transcription (Osheim et al. 1999,2002 ) to show that cleavage is not a prerequisite for termination in higher eukaryotic cells. Our results support a model in which termination in eukaryotes is dependent on an earlier event, such as recognition of polyadenylation signals by the processing machinery. Ssu72 must function at a later stage in the establishment of a cleavage-competent complex.

A recent report by Dichtl et al. (2002a) concluded that Ssu72 affects the transition between transcription elongation and termination. These investigators observed enhanced RNAP II pausing upstream of the poly(A) site in transcription run-on assays and, similar to our results, did not find a general termination defect in ssu72-2 cells. A slight increase in extended CUP1 transcripts in vivo suggested a defect in termination but was not very pronounced in comparison to that seen with cleavage-defective rna14, rna15, and pcf11 mutants (Hammell et al. 2002). Moreover, the normal mechanism for removal of unprocessed transcripts may be perturbed in the ssu72-2 mutant. Dichtl et al. (2002a) saw no effect of the ssu72-2 mutation on processing in vitro, but Ssu72 in the extract was not inactivated by heat treatment, which in our study revealed the cleavage defect. In addition, our results demonstrate a dramatic loss of $3^{\prime}$ end cleavage on depletion of Ssu72 and a rescue of processing by recombinant Ssu72 (Fig. 4C). We conclude that Ssu72 functions primarily in $3^{\prime}$ end cleavage.

Similar to Ssu72, the Sub1 protein was initially identified based on its effects on transcription initiation (Henry et al. 1996; Knaus et al. 1996). Recently, Sub1 was shown to function as an antiterminator through its interaction with Rna15 (Calvo and Manley 2001). In the present study, we demonstrate functional interactions between Pta1 and Sub1, for example, overexpression of SUB1 strongly suppressed the pta1-2 thermosensitive phenotype, and deletion of this nonessential gene is lethal in the pta1-2 mutant. The consequence of the PTA1/SUB1 interaction is the inverse of the phenotypes previously reported for the SUB1/RNA15 interaction (Calvo and Manley 2001). In this case, overexpression of SUB1 causes synthetic lethality in the rna15-1 mutant, whereas deletion of SUB1 partially suppressed the growth and termination defects of rna15-1. Overexpression of SUB1 rescues the processing defects of a pta1-2 extract (Fig. 6D). This finding suggests that even though 
Sub1 has not copurified with any of the yeast processing factors, it may indeed have a role in the cleavage step. These results also indicate that the interaction between Ptal and Subl may function in a different step from that of Rna15 with Sub1.

Interestingly, we show mutually exclusive binding of Sub1 and Ssu72 to Ptal (Fig. 7), similar to that described previously for Subl and TBP to TFIIB (Knaus et al. 1996). Furthermore, although mutually exclusive binding of Ssu72 and Sub1 to TFIIB has not been investigated, the observation that both proteins directly interact with TFIIB and that ssu72 and sub1 show the same allelespecific interactions with sua7 (Wu et al. 1999) suggests that Ssu72 and Sub1 might bind in a mutually exclusive fashion to both Ptal and TFIIB. It also suggests the possibility that displacement of one protein from its Ptal or TFIIB partner by the other protein might be an important transition point between sequential events in mRNA synthesis (Fig. 8).

Our results support the conclusion that Ssu72 and Ptal probably work together in the CPF complex to facilitate cleavage, with Ssu 72 being recruited to the $3^{\prime}$ end processing machinery through its interaction with Ptal. Surprisingly, the level of Ptal was dramatically decreased on Ssu72 depletion (Fig. 4A), whereas other processing factors remained stable. Thus, it is important for the cell to keep the levels of Ptal and Ssu72 in balance, a premise that might underlie the toxicity associated with overexpression of Ptal in the ssu72-3 mutant (Fig. 2).
Phosphorylation of the RNAP II CTD by the TFIIHassociated Kin28 kinase mediates the transition from initiation to elongation (Komarnitsky et al. 2000). Pta1 interacts genetically with Kin28, and Pta1 binds specifically to the phosphorylated form of the CTD (Rodriguez et al. 2000). Like depletion of Ssu72, the phosphorylation-defective kin28-T17D and kin28-16 mutations cause Ptal reduction without affecting other subunits of CFI and CPF. A defect in binding of CPF to unphosphorylated CTD may trigger a very specific removal of Ptal. Alternatively, Ptal might be involved in regulating the activities of both Ssu72 and Kin28.

Pta1 also interacts genetically with Spt3, a protein associated with the TFIID and SAGA complexes (Madison and Winston 1997). The interaction of Ptal with four transcription factors (Ssu72, Sub1, Kin28, and Spt3) that act at or near the promoter suggests that Ptal may be important in recruiting CPF to the initiation complex at an early stage that is then followed by interaction of the Cft1/Yhh1 subunit with the phosphorylated CTD (Dichtl et al. 2002b). This would be consistent with the localization of CPF subunits near the promoter by chromatin-immunoprecipitation (Licatalosi et al. 2002), and reminiscent of the interaction of the mammalian counterpart of CPF (CPSF) with TFIID (Dantonel et al. 1997).

A model depicting how the multiple roles of Ssu72, Pta1, and Sub1 can be integrated into the transcription cycle is shown in Figure 8. This model raises the interesting possibility that the presence of $3^{\prime}$ end processing factors at the $5^{\prime}$ end of the gene might affect the effi-

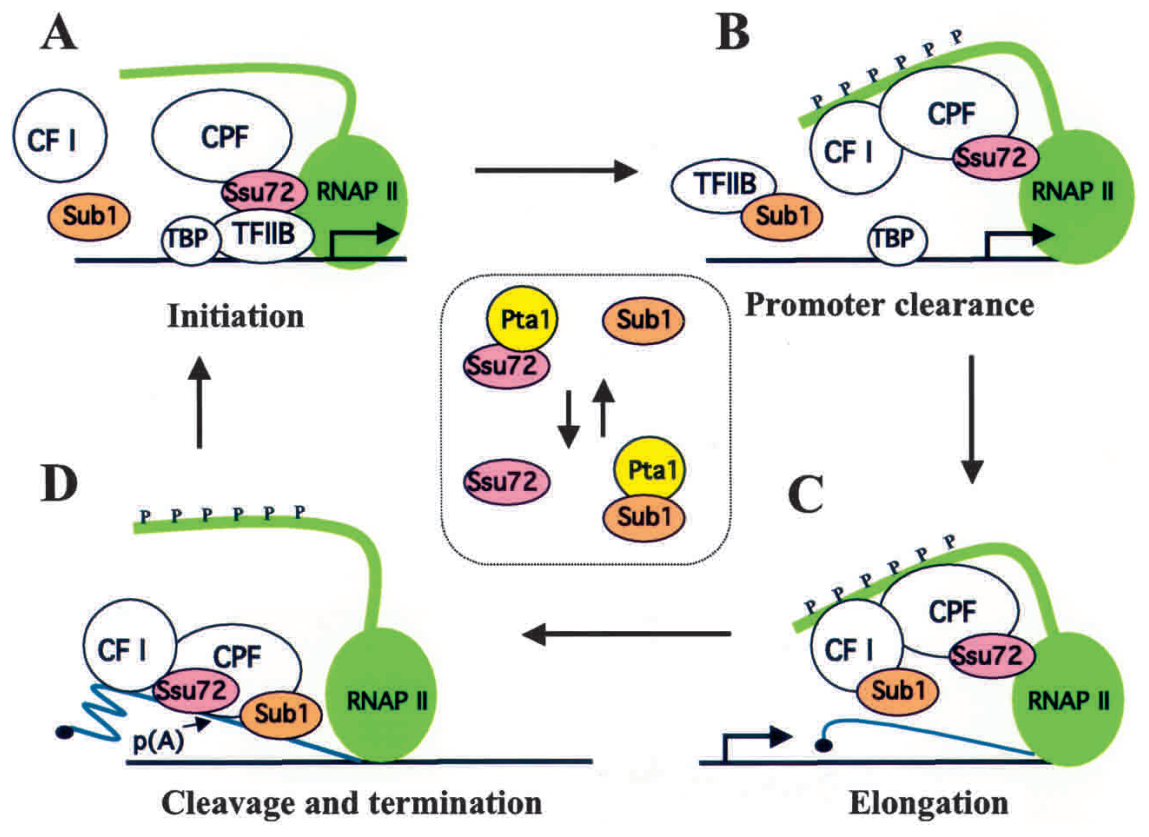
tive elongation factors, as suggested previously for Ssu72 (Dichtl et al. 2002a) and Sub1 (Calvo and Manley 2001). (D) Recognition of processing signals by CPF and CF I triggers transcription termination, in part by releasing Sub1 from CF I and perhaps transferring it to CPF, where it stimulates cleavage by releasing Ssu72 from Pta1. The inset depicts the mutually exclusive interaction of Ssu72 and Subl with Ptal during the transcription cycle. The C-terminal repeat domain of Rpbl is depicted by the green extension from RNAP II that is extensively phosphorylated $(\mathrm{P})$ in $B-D$. The blue line denotes pre-mRNA, capped at the $5^{\prime}$ end $(C, D)$ and the $3^{\prime}$ processing site shown by $\mathrm{p}(\mathrm{A})$ in $D$.
Figure 8. A model illustrating how Ssu72 and Sub1 might function at different points in the transcription cycle through interactions with TFIIB, RNAP II, cleavage/polyadenylation factor (CPF), and CF I. Based on the available data, the following scenario is possible, although several aspects need to be tested experimentally. $(A)$ In the initiation stage, Ssu72 helps to correctly position RNAP II at the promoter through direct interactions with TFIIB and RNAP II (Sun and Hampsey 1996; Pappas and Hampsey 2000; Dichtl et al. 2002a). Ssu72 also recruits CPF to the promoter through its Ptal partner and/or the weaker interactions with other CPF subunits. $(B)$ Sub1 facilitates promoter clearance by its interaction with TFIIB, possibly by disrupting the Ssu72-TFIIB interaction as well as that of TFIIB and TFIID (Knaus et al. 1996). Sub1 may be brought to the promoter by CF I through an interaction with Rna15, or alternatively, CF I could displace Sub1 from TFIIB, so that reinitiation place Subl can occur. (C) Ssu72 and Subl act as posi-

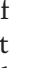

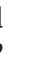

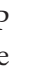


ciency of transcription initiation or promoter clearance. Such a mechanism could serve to ensure the proper loading of processing factors onto the transcriptional complex, and thus promote the likelihood of appropriate downstream processing. This would not be an absolute prerequisite for initiation, because reconstituted initiation in vitro does not require CPFs (Hampsey 1998), analogous to the observations that mRNA 3' end formation in yeast does not require coupling to RNAP II transcription (Dower and Rosbash 2002) but is greatly stimulated by it (Licatalosi et al. 2002). A precedent for the involvement of processing factors in early steps of mRNA synthesis (for review, see Manley 2002) exists in the recent findings that the U1 snRNA involved in $5^{\prime}$ splice site recognition is a functional component of the general transcription factor TFIIH (Kwek et al. 2002); that splicing factors and capping factors, as well as Ssu72, can affect elongation (Fong and Zhou 2001; Tian 2001; Dichtl et al. 2002a; Furger et al. 2002), and that the capping enzyme represses RNAP II transcription reinitiation (Myers et al. 2002). We propose that the essential role of Ssu72 lies in its activity as a cleavage factor, and that its effects on transcription initiation and elongation derive from this function, as part of the molecular mechanism coupling $3^{\prime}$ end processing with transcription. In this regard, our data showing that Ssu 72 is a bona fide cleavage factor that also affects initiation site selection provide the strongest evidence so far that $3^{\prime}$ end processing factors can influence initiation, a possibility that merits further investigation.

\section{Materials and methods}

\section{Yeast strains}

The $S$. cerevisiae strains used in this study are as follows. LRB535 (MATa his3D200 leu2-3,112 ura3-52) and its isogenic derivative YZS84 (ssu72-2) were described previously (Pappas and Hampsey 2000). YDP170 (MAT ura3-52 leu2-3,112 his3$\Delta 1$ trp1 63 ssu72::LEU2 [SSU72 TRP1 CEN]], YDP174 [ssu72-3 TRP1 CEN], and YDP177 [ssu72-7 TRP1 CEN] were constructed by plasmid-shuffle following deletion of the chromosomal SSU72 gene. The ssu72-3 and ssu72-7 alleles were generated by error-prone PCR and were identified by their thermo-sensitive growth phenotypes. Strains FY23 (MATa ura3-52 trp1 63

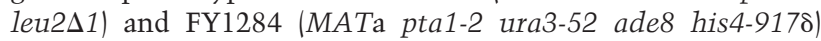
were described previously (Madison and Winston 1997). Strains

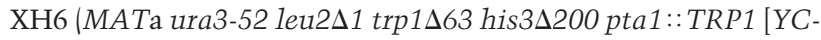

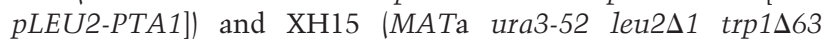
his3 200 pta1::TRP1 [YCpLEU2-pta1-3]) are an isogenic pair that have been disrupted at the chromosomal pta1 locus (pta1::TRP1) and differ from each other only by the plasmidborne pta1 allele, either PTA1 $1^{+}$or pta1-3, which was generated by deletion of 285 amino acids from the C terminus of Pta1. FY23 was used as the host to construct the PTA1-TAP and SSU72-td strains. The rna14-1 (MATa ura3-1 trp1-1 ade2-1 leu2-3,112 his3-11,15 rna14-1), rna15-1 (MATa ura3-1 trp1-1 ade2-1 leu2-3,112 his3-11,15 rna15-1), and rna15-2 (MATa ura3-1 trp1-1 ade2-1 leu2-3,112 his3-11,15 rna15-2) strains are described elsewhere (Minvielle-Sebastia et al. 1991).

The PTA1-TAP strain was generated by inserting the TAP sequence immediately upstream of the stop codon of PTA1 as previously described (Puig et al. 2001) In brief, a TAP-TRP1 (KL) bracketed by sequences flanking the PTA1 stop codon was amplified by PCR with pBS1479 as a template by using Deep Vent DNA polymerase (Biolabs) and primers Ptal-tag-For (5'-GAT GAAGGCTTACACAAGCAGTGCGATTCACTGCTTGACA GGCTAAAAAAGAGAAGATGGAAAAAGAA-3') and Ptaltag-Rev (5'-TAGCACAGAATGATAGATAAAACATTGATTT GCAAGTTGAAGGAAGACACGACTCACTATAGGGCG-3'). Each primer has a pBS1479 specific sequence (underlined) and a 48-base PTA1-specific sequence. FY23 cells were transformed with the Ptal-TAP-TRP1 PCR product, followed by selection for the TRP1 marker. Transformants harboring PTA1-TAPTRP1 were verified by PCR and Southern blot. The expression of Pta1-TAP was confirmed by Western blot.

The pSsu72-degron plasmid was constructed by insertion of the first $200 \mathrm{bp}$ of the SSU72 open reading frame (ORF) into the HindIII site of plasmid pPW66R (Dohmen et al. 1994). The SSU72-td strain was constructed by transformation of FY23 with the pSsu72-degron plasmid linearized at the ClaI site (nucleotide 150 relative to start codon in the SSU72 ORF). Integration of plasmid DNA at the SSU72 locus generated an ORF encoding Ubiquitin-Arg-DHFR ${ }^{\text {ts }}$-HA-Ssu72.

\section{Affinity purification of TAP-tagged Pta1 and its associated proteins}

Yeast expressing TAP-tagged Ptal were grown in $2 \mathrm{~L}$ of YPD at $30^{\circ} \mathrm{C}$ to an $\mathrm{OD}_{600}=1.5$ to 2.5 . Extracts were prepared as described previously (Zhao et al. 1999b; Gross and Moore 2001), except omitting the ammonium sulfate precipitation step. Proteins were purified according to the standard TAP procedure (Puig et al. 2001), separated on an SDS-10\% polyacrylamide gel, and detected by silver staining. The known CPF subunits were confirmed by Western blot analysis. Novel proteins were identified by mass spectrometry using the Core Laboratory for Protein Microsequencing and Proteomic Mass Spectrometry, University of Massachusetts Medical School.

\section{Immunoprecipitation and Western blotting}

Yeast whole-cell extracts $(500 \mu \mathrm{g})$ or recombinant proteins were incubated with antibody bound to protein A agarose beads (GIBCO-BRL) for $2 \mathrm{~h}$ at $4^{\circ} \mathrm{C}$ in $200 \mu \mathrm{L}$ of buffer IP-150 (10 mM Tris- $\mathrm{HCl}$ at $\mathrm{pH} 7.9,150 \mathrm{mM} \mathrm{NaCl}, 1 \mathrm{mM}$ EDTA, $10 \%$ glycerol, $1 \mathrm{mM}$ DTT, $1 \mathrm{mM}$ PMSF, $2 \mu \mathrm{M}$ pepstatin-A, $0.6 \mu \mathrm{M}$ leupeptin, $0.01 \% \mathrm{NP}-40$, and $150 \mu \mathrm{g} / \mathrm{mLBSA})$. Samples were centrifuged, and the pellets were washed four times with $400 \mu \mathrm{L}$ of the buffer IP-150 with $0.05 \%$ NP-40. The pellets were resuspended in 15 $\mu \mathrm{L}$ of SDS sample buffer. Aliquots of the pellets and supernatants were analyzed by SDS-10\% polyacrylamide gel. Western blotting was performed according to standard procedures.

\section{Recombinant proteins and in vitro protein-protein} interaction assays

Plasmid pGST-Ptal was generated by insertion of full-length PTA1 into the SmaI site of pGEX-2TK vector. Plasmid pGSTSsu72 was created by cloning the full-length SSU72 into the BamHI and EcoRI sites of the pGEX-2TK. Plasmid pGST-TFIIB was described previously (Wu et al. 1999). Plasmid pSsu72-His6 was created by cloning the SSU72 ORF into plasmid pET21b (Pharmacia) using the NdeI and NotI cloning sites. Recombinant proteins were expressed in and purified from E. coli BL21(DE3) pLysS as described previously (Gross and Moore 2001). Radiolabeled proteins used in this study were generated in vitro with the TNT rabbit reticulocyte lysate system (Pro- 
mega) in the presence of $\left[{ }^{35} \mathrm{~S}\right]$-methionine in a total volume of 50 $\mu \mathrm{L}$. GST-Pta1, GST-Ssu72, or GST was incubated with $20 \mu \mathrm{L}$ of bed volume of glutathione-Sepharose beads in $200 \mu \mathrm{L}$ of buffer IP- 150 for $1 \mathrm{~h}$ at $4^{\circ} \mathrm{C}$. After extensive washing, proteins bound to the beads were incubated with radiolabeled proteins $(1-5 \mu \mathrm{L}$ of the in vitro translation reaction) for $2 \mathrm{~h}$ at $4^{\circ} \mathrm{C}$. In some cases, samples were treated with $15 \mu \mathrm{g}$ of RNAse A for $30 \mathrm{~min}$ at $25^{\circ} \mathrm{C}$. Beads were pelleted and washed four times with $400 \mu \mathrm{L}$ of buffer IP- 150 with $0.05 \%$ NP-40. Proteins were eluted in $15 \mu \mathrm{L}$ of SDS sample buffer and resolved by SDS-10\% polyacrylamide gel.

\section{Overexpression of PTA1}

Plasmid pYES-PTA1 (GALp-PTA1 URA3) was kindly provided by J. Patrick O'Connor (University of Medicine and Dentistry of New Jersey-New Jersey Medical School, Newark). The plasmid pYES-PTA1 was introduced into isogenic strains LRB535 $\left(S S U 72^{+}\right)$and YZS84 (ssu72-2), or YDP170 (SSU72 $)$, YDP174 (ssu72-3), and YDP177 (ssu72-7). $\mathrm{Ura}^{+}$transformants were streaked on Ura omission medium containing either $2 \%$ glucose or $2 \%$ galactose as the sole carbon source and incubated at $30^{\circ} \mathrm{C}$.

\section{Deletion and overexpression of SUB1}

The pta1-2 mutant was transformed with plasmid YCp-PTA1 (O'Connor and Peebles 1992). SUB1 was deleted from the chromosome of the resulting strain by kanMX6 insertion (Longtine et al. 1998) and confirmed by PCR. For SUB1 overexpression, pta1 mutant strains were transformed with pRS-SUB1, which was generated by cloning $S U B 1$ and its promoter region into the $2 \mu$ HIS3 vector pRS423, or with vector alone. Transformants were incubated on medium lacking histidine at either $30^{\circ} \mathrm{C}$ or $37^{\circ} \mathrm{C}$.

Whole cell extract preparations and in vitro $3^{\prime}$ end processing assays

Yeast whole-cell extracts, preparation of ${ }^{32} \mathrm{P}$-labeled full-length GAL7 RNA and precleaved GAL7 RNA, and in vitro 3' end processing assays were carried out as described previously (Chen and Moore 1992; Zhao et al. 1999b; Gross and Moore 2001).

\section{RNA analysis}

Total RNA was extracted from yeast by the hot phenol method (Sparks and Dieckmann 1998). Poly(A) ${ }^{+}$RNA was purified from $100 \mu \mathrm{g}$ of total RNA using the QIAGEN Oligotex kit. Poly(A) ${ }^{+}$ RNA was separated on a $1.2 \%$ formaldehyde-agarose gel and transferred to Hybond $\mathrm{N}^{+}$membrane. Probes were radiolabeled with ${ }^{32} \mathrm{P}$-dATP by using a random primer kit (Biolabs). Northern hybridization was performed as described by Sparks and Dieckmann (1998). Transcription run-on analysis was performed as described in Birse et al. (1998).

\section{Acknowledgments}

We thank N. Proudfoot and E. Prescott for the TRO kit and helpful advice; H. Domdey for antibodies against CPF subunits; D. Dawson for suggesting the Degron strategy; Marián FreirePicos for constructing ssu72 mutants; E. Nedea and J. Greenblatt for communicating unpublished results; and F. Lacroute, C. Peebles, P. O'Connor, and F. Winston for strains and plasmids.
This work was supported by the N.I.H. grant GM41752 to C. Moore and N.I.H. grant GM39484 to M. Hampsey.

The publication costs of this article were defrayed in part by payment of page charges. This article must therefore be hereby marked "advertisement" in accordance with 18 USC section 1734 solely to indicate this fact.

\section{References}

Bentley, D. 2002. The mRNA assembly line: Transcription and processing machines in the same factory. Curr. Opin. Cell Biol. 14: 336-342.

Birse, C.E., Minvielle-Sebastia, L., Lee, B.A., Keller, W., and Proudfoot, N.J. 1998. Coupling termination of transcription to messenger RNA maturation in yeast. Science 280: 298301.

Calvo, O. and Manley, J.L. 2001. Evolutionarily conserved interaction between CstF-64 and PC4 links transcription, polyadenylation, and termination. Mol. Cell 7: 1013-1023.

Chen, J. and Moore, C. 1992. Separation of factors required for cleavage and polyadenylation of yeast pre-mRNA. Mol. Cell. Biol. 12: 3470-3481.

Dantonel, J.C., Murthy, K.G., Manley, J.L., and Tora, L. 1997. Transcription factor TFIID recruits factor CPSF for formation of 3' end of mRNA. Nature 389: 399-402.

Dichtl, B., Blank, D., Ohnacker, M., Friedlein, A., Roeder, D., Langen, H., and Keller, W. 2002a. A role for SSU72 in balancing RNA polymerase II transcription elongation and termination. Mol. Cell 10: 1139-1150.

Dichtl, B., Blank, D., Sadowski, M., Hubner, W., Weiser, S., and Keller, W. 2002b. Yhhlp/Cftlp directly links poly(A) site recognition and RNA polymerase II transcription termination. EMBO J. 21: 4125-4135.

Dohmen, R.J., Wu, P., and Varshavsky, A. 1994. Heat-inducible degron: A method for constructing temperature-sensitive mutants. Science 263: 1273-1276.

Dower, K. and Rosbash, M. 2002. T7 RNA polymerase-directed transcripts are processed in yeast and link $3^{\prime}$ end formation to mRNA nuclear export. RNA 8: 686-697.

Edmonds, M. 2002. A history of poly A sequences: From formation to factors to function. Prog. Nucleic Acid Res. Mol. Biol. 71: 285-389.

Fong, Y.W. and Zhou, Q. 2001. Stimulatory effect of splicing factors on transcriptional elongation. Nature 414: 929-933.

Furger, A., O'Sullivan, J.M., Binnie, A., Lee, B.A., and Proudfoot, N.J. 2002. Promoter proximal splice sites enhance transcription. Genes \& Dev. 16: 2792-2799.

Gavin, A.C., Bosche, M., Krause, R., Grandi, P., Marzioch, M., Bauer, A., Schultz, J., Rick, J.M., Michon, A.M., Cruciat, C.M., et al. 2002. Functional organization of the yeast proteome by systematic analysis of protein complexes. Nature 415: 141-147.

Ge, H., Zhao, Y., Chait, B.T., and Roeder, R.G. 1994. Phosphorylation negatively regulates the function of coactivator PC4. Proc. Nat1. Acad. Sci. 91: 12691-12695.

Gross, S. and Moore, C. 2001. Five subunits of Saccharomyces cerevisiae cleavage factor I are required for reconstitution of the cleavage and polyadenylation activities. Proc. Natl. Acad. Sci. 98: 6080-6085.

Hammell, C., Gross, S., Zenklusen, D., Heath, C., Stutz, F., Moore, C., and Cole, C. 2002. Coupling of termination, $3^{\prime}$ processing and mRNA export. Mol. Cell. Biol. 22: $6441-6457$.

Hampsey, M. 1998. Molecular genetics of the RNA polymerase II general transcriptional machinery. Microbiol. Mol. Biol. 
Rev. 62: 465-503.

Henry, N.L., Bushnell, D.A., and Kornberg, R.D. 1996. A yeast transcriptional stimulatory protein similar to human PC4. J. Biol. Chem. 271: 21842-21847.

Howe, K. 2002. RNA polymerase II conducts a symphony of pre-mRNA processing activities. Biochim. Biophys. Acta 1577: 308-324.

Knaus, R., Pollock, R., and Guarente, L. 1996. Yeast SUB1 is a suppressor of TFIIB mutations and has homology to the human co-activator PC4. EMBO J. 15: 1933-1940.

Komarnitsky, P., Cho, E.J., and Buratowski, S. 2000. Different phosphorylated forms of RNA polymerase II and associated mRNA processing factors during transcription. Genes \& Dev. 14: 2452-2460.

Kwek, K.Y., Murphy, S., Furger, A., Thomas, B., O'Gorman, W., Kimura, H., Proudfoot, N.J., and Akoulitchev, A. 2002. U1 snRNA associates with TFIIH and regulates transcriptional initiation. Nat. Struct. Biol. 9: 800-805.

Licatalosi, D.D., Geiger, G., Minet, M., Schroeder, S., Cilli, K., McNeil, J.B., and Bentley, D.L. 2002. Functional interaction of yeast pre-mRNA $3^{\prime}$ end processing factors with RNA polymerase II. Mol. Cell 9: 1101-1111.

Longtine, M.S., McKenzie, A., Demarini, D.J., Shah, N.G., Wach, A., Brachat, A., Philippsen, P., and Pringle, J.R. 1998. Additional modules for versatile and economical PCR-based gene deletion and modification in Saccharomyces cerevisiae. Yeast 14: 953-961.

Madison, J.M. and Winston, F. 1997. Evidence that Spt3 functionally interacts with Mot1, TFIIA, and TATA- binding protein to confer promoter-specific transcriptional control in Saccharomyces cerevisiae. Mol. Cell. Biol. 17: 287-295.

Mandart, E. 1998. Effects of mutations in the Saccharomyces cerevisiae RNA14 gene on the abundance and polyadenylation of its transcripts. Mol. Gen. Genet. 258: 16-25.

Maniatis, T. and Reed, R. 2002. An extensive network of coupling among gene expression machines. Nature 416: 499-506.

Manley, J. 2002. Nuclear coupling: RNA processing reaches back to transcription. Nat. Struct. Biol. 9: 790-791.

Minvielle-Sebastia, L., Winsor, B., Bonneaud, N., and Lacroute, F. 1991. Mutations in the yeast RNA14 and RNA15 genes result in an abnormal mRNA decay rate: Sequence analysis reveals an RNA-binding domain in the RNA15 protein. Mol. Cell. Biol. 11: 3075-3087.

Minvielle-Sebastia, L., Preker, P.J., and Keller, W. 1994. RNA14 and RNA15 proteins as components of a yeast pre-mRNA 3 '-end processing factor. Science 266: 1702-1705.

Myers, L.C., Lacomis, L., Erdjument-Bromage, H., and Tempst, P. 2002. The yeast capping enzyme represses RNA polymerase II transcription. Mol. Cell 10: 883-894.

O'Connor, J.P. and Peebles, C.L. 1992. PTA1, an essential gene of Saccharomyces cerevisiae affecting pre-tRNA processing. Mol. Cell. Biol. 12: 3843-3856.

Orphanides, G. and Reinberg, D. 2002. A unified theory of gene expression. Cell 108: 439-451.

Osheim, Y.N., Proudfoot, N.J., and Beyer, A.L. 1999. EM visualization of transcription by RNA polymerase II: Downstream termination requires a poly(A) signal but not transcript cleavage. Mol. Cell 3: 379-387.

Osheim, Y.N., Sikes, M.L., and Beyer, A.L. 2002. EM visualization of Pol II genes in Drosophila: Most genes terminate without prior $3^{\prime}$ end cleavage of nascent transcripts. Chromosoma 111: 1-12.

Pappas Jr., D.L. and Hampsey, M. 2000. Functional interaction between Ssu72 and the Rpb2 subunit of RNA polymerase II in Saccharomyces cerevisiae. Mol. Cell. Biol. 20: 8343-8351.

Preker, P.J., Ohnacker, M., Minvielle-Sebastia, L., and Keller, W.
1997. A multisubunit $3^{\prime}$ end processing factor from yeast containing poly(A) polymerase and homologues of the subunits of mammalian cleavage and polyadenylation specificity factor. $E M B O T$. 16: 4727-4737.

Proudfoot, N.J., Furger, A., and Dye, M.J. 2002. Integrating mRNA processing with transcription. Cell 108: 501-512.

Puig, O., Caspary, F., Rigaut, G., Rutz, B., Bouveret, E., BragadoNilsson, E., Wilm, M., and Seraphin, B. 2001. The tandem affinity purification (TAP) method: A general procedure of protein complex purification. Methods 24: 218-229.

Rodriguez, C.R., Cho, E.J., Keogh, M.C., Moore, C.L., Greenleaf, A.L., and Buratowski, S. 2000. Kin28, the TFIIH-associated carboxy-terminal domain kinase, facilitates the recruitment of mRNA processing machinery to RNA polymerase II. Mol. Cell. Biol. 20: 104-112.

Roguev, A., Schaft, D., Shevchenko, A., Pijnappel, W., Wilm, M., Aasland, R., and Stewart, A. 2001. The Saccharomyces cerevisiae Set1 complex includes an Ash2 homologue and methylates histone 3 lysine 4. EMBO J. 20: 7137-7148.

Shatkin, A. and Manley, J. 2000. The ends of the affair: capping and polyadenylation. Nat. Struct. Biol. 7: 838-842.

Sparks, K. and Dieckmann, C. 1998. Regulation of poly(A) site choice of several yeast mRNAs. Nucleic Acids Res. 26: $4676-4687$.

Sun, Z.W. and Hampsey, M. 1996. Synthetic enhancement of a TFIIB defect by a mutation in SSU72, an essential yeast gene encoding a novel protein that affects transcription start site selection in vivo. Mol. Cell. Biol. 16: 1557-1566.

Tian, H. 2001. RNA ligands generated against complex nuclear targets indicate a role for U1 snRNP in co-ordinating transcription and RNA splicing. FEBS Lett. 509: 282-286.

Torchet, C., Bousquet-Antonelli, C., Milligan, L., Thompson, E., Kufel, J., and Tollervey, D. 2002. Processing of 3'-extended read-through transcripts by the exosome can generate functional mRNAs. Mol. Cell 9: 1285-1296.

Tran, D.P., Kim, S.J., Park, N.J., Jew, T.M., and Martinson, H.G. 2001. Mechanism of poly(A) signal transduction to RNA polymerase II in vitro. Mol. Cell. Biol. 21: 7495-7508.

Vo, L.T., Minet, M., Schmitter, J.M., Lacroute, F., and Wyers, F. 2001. Mpe1, a zinc knuckle protein, is an essential component of yeast cleavage and polyadenylation factor required for the cleavage and polyadenylation of mRNA. Mol. Cell. Biol. 21: 8346-8356.

Wahle, E. and Ruegsegger, U. 1999. 3'-End processing of premRNA in eukaryotes. FEMS Microbiol. Rev. 23: 277-295.

Walsh, E.P., Lamont, D.J., Beattie, K.A., and Stark, M.J. 2002. Novel interactions of Saccharomyces cerevisiae type 1 protein phosphatase identified by single-step affinity purification and mass spectrometry. Biochemistry 41: 2409-2420.

Wu, W.H., Pinto, I., Chen, B.S., and Hampsey, M. 1999. Mutational analysis of yeast TFIIB: A functional relationship between Ssu72 and Sub1/Tsp1 defined by allele-specific interactions with TFIIB. Genetics 153: 643-652.

Zhao, J., Hyman, L., and Moore, C. 1999a. Formation of mRNA 3 ' ends in eukaryotes: Mechanism, regulation, and interrelationships with other steps in mRNA synthesis. Microbiol. Mol. Biol. Rev. 63: 405-445.

Zhao, J., Kessler, M., Helmling, S., O'Connor, J.P., and Moore, C. 1999b. Pta1, a component of yeast CF II, is required for both cleavage and poly(A) addition of mRNA precursor. Mol. Cell. Biol. 19: 7733-7740. 


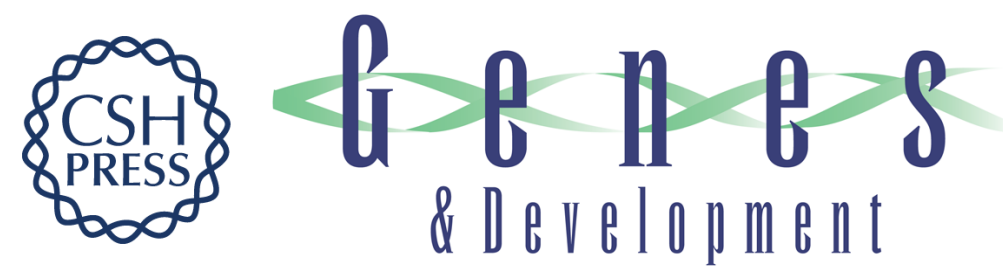

\section{Functional interactions between the transcription and mRNA $3^{\prime}$ end processing machineries mediated by Ssu72 and Sub1}

Xiaoyuan He, Asad U. Khan, Hailing Cheng, et al.

Genes Dev. 2003, 17:

Access the most recent version at doi:10.1101/gad.1075203

References This article cites 53 articles, 26 of which can be accessed free at: http://genesdev.cshlp.org/content/17/8/1030.full.html\#ref-list-1

License

Email Alerting

Receive free email alerts when new articles cite this article - sign up in the box at the top Service right corner of the article or click here.

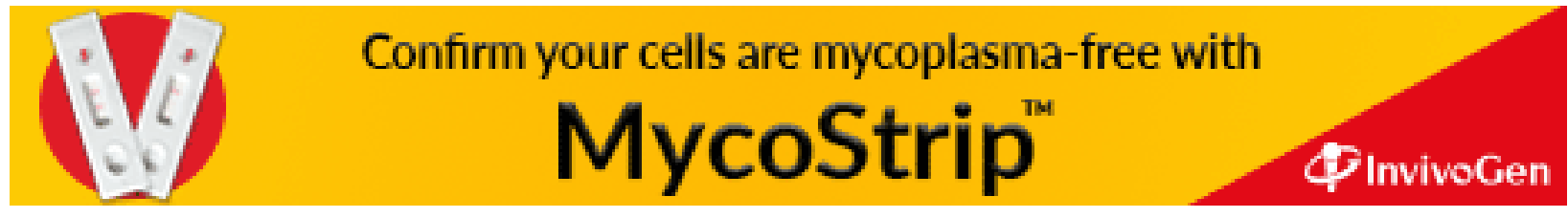

